\title{
Toxicity Assessment of Structurally Relevant Natural Products from Mexican Plants with Antinociceptive Activity
}

\author{
Karina Martinez-Mayorga, ${ }^{1, *}$ Andrés F. Marmolejo-Valencia, ${ }^{1}$ Fernando Cortes-Guzman, ${ }^{1}$ \\ Juan Carlos García-Ramos, ${ }^{1, \S}$ Eric Iván Sánchez-Flores, ${ }^{1}$ Joaquín Barroso-Flores, ${ }^{1}$ \\ Jose L. Medina-Franco, ${ }^{2}$ and Baldomero Esquivel-Rodriguez ${ }^{1}$ \\ 1 Instituto de Química, Universidad Nacional Autónoma de México, Mexico City, Mexico. C.P. 04510 \\ 2 Facultad de Química, Departamento de Farmacia, Universidad Nacional Autónoma de México, Mexico City, Mexico. \\ * Corresponding author: Email: kmtzm@unam.mx, phone: +52-55-5622-4770 (Ext. 4614), fax: +52-55-5616-2217 \\ $\S$ current address: CONACYT-UNAM-Centro de Nanociencias y Nanotecnología. Km 107 Carretera Tijuana-Ensenada. \\ Ensenada, B.C. México. C.P. 22860
}

Received, December 13 ${ }^{\text {th }}, 2016$; Accepted, March $9^{\text {th }}, 2017$.

\begin{abstract}
UNIIQUIM database contains molecules from Mexican plants, one of the richest sources of bioactive molecules in the world. Here, we describe the chemical and toxicological profile of molecules with analgesic activity from UNIIQUIM. Most of the compounds are likely to interact with opioid receptors. The predicted acute toxicity is low and none is predicted mutagenic. Given the structural diversity, and biological and toxicity profiles, these molecules represent a new avenue in the search of molecules with antinociceptive activity.

Keywords: UNIIQUIM; traditional Mexican medicine; analgesics; nociception; toxicity profile.
\end{abstract}

\section{Introduction}

Mexican flora is among the five richest in the world in terms of diversity and structural complexity of their secondary metabolites including peptides, flavonoids, alkaloids, and terpenes, among others. The first steps towards systematic studies of this chemically and structurally rich content are given by the UNIIQUIM (Unidad de Informática del Instituto de Química) group and the CCUD (Coordinación de Colecciones Universitarias Digitales) supported by the National Autonomous University of Mexico (UNAM). Natural products play a central role in traditional medicine, nutrition and in drug discovery. Databases of natural products, drugs and nutraceuticals have been created and allow the storage and analysis of chemical information in an efficient and systematic manner. This allows for example assessing diversity and structural novelty, the design of chemical libraries and the qualitative and quantitative studies of structure-activity relationships (SAR, QSAR), the prediction of ADME-Tox properties (absorption, distribution, metabolism, excretion and toxicity). The handling and analysis of chemical databases has been the starting point on drug discovery, the methodologies are general and its use has been expanded to agrochemistry, chemical of flavors, and environmental chemistry, to name few examples.

The use of plants and other natural products as traditional medicine not only conduced to the discovery of opiates as
Resumen. La base de datos UNIIQUIM contiene moléculas de plantas mexicanas, una de las fuentes más ricas de moléculas bioactivas en el mundo. Aquí se describe la química y el perfil toxicológico de moléculas con actividad analgésica obtenidas de UNIIQUIM. La mayoría de los compuestos son propensos a interactuar con los receptores opioides. La toxicidad aguda predicha es baja y ningún compuesto se predice mutagénico. Dada su diversidad estructural y su perfil biológico y toxicológico, son atractivas moléculas líderes con actividad antinociceptiva.

Palabras clave: UNIIQUIM; medicina tradicional Mexicana; analgésicos; nocicepción; perfil toxicológico.

potent analgesics, but also to compounds with high selectivity towards specific receptors and unusual molecular scaffolds. One of the compounds that had a profound impact in the opioid field is salvinorin A. This compound, obtained and characterized for the first time in 1982 by Dr. Alfredo Ortega in the Institute of Chemistry at UNAM [1], is a psychotropic terpenoid found in the plant Salvia divinorum, an indigenous plant from southern Mexico. This molecule is the first known opioid ligand that is not an alkaloid given the fact that it bears no basic nitrogen atoms [2]. This outstanding discovery exemplifies the relevance of natural products and advocates for the exploration and analysis of other compounds of this type.

Better understanding of the different biological mechanisms involved in pain modulation has allowed exploring and designing new molecules with a wide range of affinity and selectivity with the ultimate goal of attenuating undesirable side effects. Molecular modeling studies have contributed in this regard. We are actively working on opioid receptors and its ligands, including those obtained from Mexican plants. For example, we have contributed on the exploration of conformational preferences of opioid peptides into the kappa opioid receptor [3], and the identification of probable binding modes for relevant opioid agonists [4,5]. Molecules with known structural and biological properties are useful as reference. For instance, morphine, herkinorin, DAMGO and naloxone have affinity to the $\mu$-opioid receptor. While morphine is an opiate 
benzylisoquinoline alkaloid, mainly extracted from poppy straw of the opium poppy, herkinorin is a semi synthetic analogue of salvinorin A, obtained by deacetylation [6], and DAMGO is a synthetic peptide analogous to enkephalines [7]. In turn, naloxone is an opioid antagonist, it is used to block the effects of opioids, especially in patients who are exposed to overdose [8]. Little to no effect is observed when administered in the absence of opioids. A popular formulation of oxycodone/ naloxone is available for controlled release of the former [9]. These molecules represent an opioid-related set of structurally diverse molecules and from diverse sources.

Natural products usually have pharmacological or biological activity. However, some products may be toxic for humans, insects, etc. Thus natural products may show dual roles, depending on the targets for treatment. The toxicity of natural products against cancer cells, viruses, germs, or bacteria has been revised.

The distinct characteristics of the chemical structures of natural products have played a key role in its historic development as lead compounds or sources of active molecules. Key distinct features of natural products are, in general, molecular diversity including coverage in chemical space, structural complexity, and physicochemical properties. These features have been measured and analyzed qualitatively and quantitatively using a broad range of computational approaches.

Recent studies focused on the comparison of natural products with a variety of databases have shown that natural products are distinct in terms of the number of aromatic rings and complex ring systems, the number of chiral centers, the number and proportions of heteroatoms and the degree of saturation [10], have large molecular complexity [11] and adequate drug-like physicochemical properties [12] [13].

Based on the aim to "fail early" in the drug discovery pipeline, it is advantageous to identify and deprioritize molecules with low probability of success, for instance based on ADME-Tox properties. Scientist and society learned the importance to focus on toxicity as a key aspect on the proposal of new molecules as potential therapeutic or diagnostic agents. An example with devastating consequences is the thalidomide tragedy, reported the mid 60's [14] representing a turning point in toxicity testing. This public health problem prompted to several governments and international regulatory agencies to develop systematic and rigorous toxicity testing protocols on compounds intended for human consumption before going to market. In this sense, the most accepted general toxicity testing guidelines for chemicals are those published by the Organization for Economic Cooperation and Development (OECD). These guidelines are reviewed and updated periodically by expert committees to meet the scientific progress and ever changing assessment practices. Similar recommendations can be found in the fourth revised edition of the Globally Harmonized System of Classification and Labelling of Chemicals (GHS). The most recently revised guidelines for Acute, Sub-chronic and Chronic Oral Toxicity Studies are listed in Table 1.

Particularly for pharmaceuticals, the International Conference on Harmonisation of Technical Requirements for Registration of Pharmaceuticals for Human Use (ICH) has developed universally accepted guidelines for acute, sub-chronic, and chronic toxicity testing of pharmaceuticals, which have been accepted by regulatory agencies in all member countries, i.e., US, Europe and Japan (http://www.ich.org/home.html). Even though acute toxicity is no longer recommended for development of pharmaceuticals and regardless which of the toxicological test recommendations are being considered, some terms have to be established to determine the toxicity of different substances studied. According to GSH, substances can be allocated on one of five toxicity categories based on acute toxicity numeric cut-off criteria. For oral acute toxicity expressed as

Table 1. Acute, subchronic and chronic oral toxicity study guidelines.

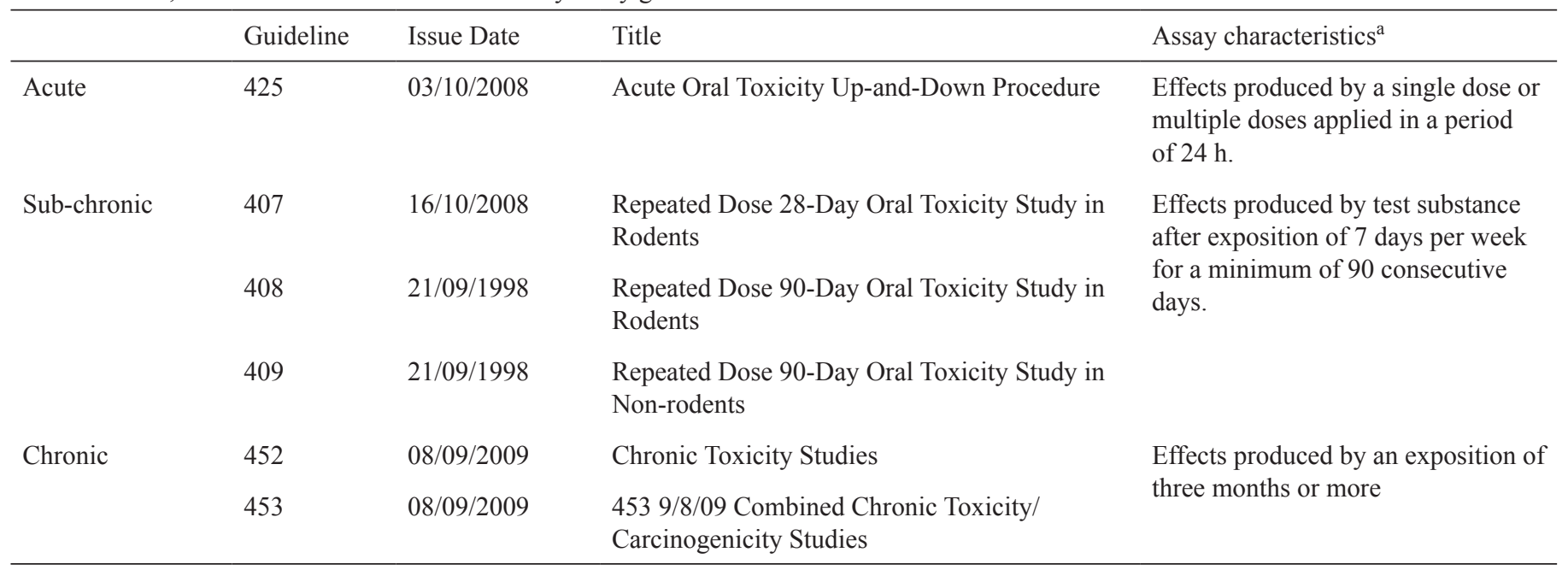

${ }^{a}$ Guidance for industry and other stakeholders toxicological principles for the safety assessment of food Ingredients. Redbook 2000. U.S. Department of Health and Human Services. Food and Drug Administration. Center for Food Safety and Applied Nutrition. July 2000; updated July 2007. 
medium lethal dose $\left(\mathrm{LD}_{50}\right)$ is as follows: Category 1: $5 \mathrm{mg} / \mathrm{Kg}$ bodyweight, Category 2: $50 \mathrm{mg} / \mathrm{Kg}$ bodyweight, Category 3: $300 \mathrm{mg} / \mathrm{Kg}$ bodyweight, Category 4: $2000 \mathrm{mg} / \mathrm{Kg}$ bodyweight and Category 5: $5000 \mathrm{mg} / \mathrm{Kg}$ bodyweight. Medium Lethal Dose $\left(\mathrm{LD}_{50}\right)$ is the concentration of a substance required to kill half members of a tested population after a specific test duration. Historically obtained by a single dose protocol, nowadays the Up-and Down procedure is employed to decrease the number of animals employed [15]. The toxicity of the compounds can manifest as damage to the genetic material or cellular components, this is associated with the functionality of chromosomes inside cell causing mutations; defined as a permanent change in the amount or structure of the genetic material in a cell. The term mutation applies to both, to heritable genetic changes that may be manifested at the phenotypic level, and to the underlying DNA modification when known, including for example, specific base pair changes and chromosomal translocations. When a compound gives rise to an increased occurrence of mutations in populations of cells and/or organisms, the term mutagenic is used. In both cases, the Ames Assay is one of the most commonly test employed.

During the past 30 years, QSAR methodologies have gradually and greatly evolved [16]. The original use for the quantification of structure-activity relationships widened to environmental toxicology, and QSAR models are now accepted for regulatory purposes [17]. The International Conference on Harmonisation (ICH)-M7 guideline provides a practical framework that is applicable to the identification, categorization, qualification, and control of these mutagenic impurities to limit potential carcinogenic risk [18]. Regarding (Q)SAR models, ICH-M7 states "A computational toxicology assessment should be performed using $(\mathrm{Q}) \mathrm{SAR}$ methodologies that predict the outcome of a bacterial mutagenicity assay [19]. Two (Q)SAR prediction methodologies that complement each other should be applied. One methodology should be expert rule-based and the second methodology should be statistical-based." (Q)SAR models should follow the general validation principles set forth by the Organization for Economic Co-operation and Development (OECD) [20]. Expert knowledge can be used to review any computer system-based analysis, highlighting the relevance of expert review to provide additional supportive evidence on decision making [17,21,22]. The interpretation of models, in the framework of ICH-M7 is based on structural alerts. Compounds are considered mutagenic or non-mutagenic based on the absence, presence or contradictory structural alerts from two complementary (Q)SAR methodologies (expert rulebased and statistical) allowing to state if further testing is recommended.

To continue our efforts on the study of natural products particularly those with antinociception activity, in this work, we present the chemical and toxicological description of compounds with analgesic properties extracted from Mexican plants. Relevant molecules are included as reference, and the toxicological profile includes the prediction of oral rat $\mathrm{IC}_{50}$ values, and mutagenic risk assessment.

\section{Results and Discussion}

Compounds with analgesic or antinociceptive activity from Mexican plants obtained from UNIIQUIM are summarized in Fig. 1. These molecules include flavonoids, terpenes, alkaloids, etc. For comparison, we included molecules with relevance in analgesia, named: DAMGO, herkinorin, morphine, naloxone, and salvinorin A. These reference molecules, particularly target opioid receptors, which are the main targets for chronic pain, for instance in post-operatory and cancer patients.

A great structural diversity is found in compounds with analgesic or nociceptive activity. Literature suggest that the pharmacophore requires the presence of hydrophobic groups, hydorgen bond donors and hydrogen bond acceptors. However, some of the compounds studied in this work do not satisfy this requirement, but show an important analgesic activity with low toxicities.

Morphine was the first medicinal alkaloid isolated from any plant and one of the most effective treatment for pain [23]. A study conducted by Dykstra shows that morphine completely blocks acid-induced writhing with a dose of $3.2(\mathrm{mg} / \mathrm{Kg})$ or $0.011 \mathrm{mmol} / \mathrm{Kg}$ [24]. Results for acacetin $(0.11 \mathrm{mmol}, 72.5 \%)$, lupenone ( $0.011 \mathrm{mmol}, 50 \%$; $0.023 \mathrm{mmol}, 60-65 \%)$, epi-friedelanol $(0.023 \mathrm{mmol}, 45.83 \%)$, linarin $(0.042 \mathrm{mmol}, 38 \%$; $0.337 \mathrm{mmol}, 57 \%)$, taraxasteryl acetate $(0.021 \%, 77.36 \%)$ and caryophyllene oxide $(0.056 \mathrm{mmol}, 57.87 \%$; $0.113 \mathrm{mmol}$, $75.19 \%$ ) were found with the same methodology. None of them show a better activity than morphine, but some show comparable inhibition such as lupenone and taraxasteryl acetate.

Other interesting example is caryophyllene oxide that inhibits the acid-induced writhing in $75 \%$, with a dose ten times higher than that found for morphine, but with a 10-fold decrease in toxicity (caryophyllene oxide $\mathrm{LD}_{50}=10.7 \mathrm{mmol} / \mathrm{Kg}$, Table 3. Regarding toxicity, all studied compounds showed lower effect than morphine with a decrease of 4 to 10 -fold in the $\mathrm{LD}_{50}$ values, with exception of acacetin, that is practically as toxic as morphine. It is important to note that all studied compounds lack the structural requirements suggested in the literature as key features for their interaction with opioid receptors. However, tests like hot plate or tail-flick suggest that these compounds (linarine, taraxasteryl acetate and caryophyllene oxide) might be targeting opioid receptors. Due to the structural similarity of epi-friedelanol, taraxterol and lupenone with taraxasteryl acetate and similarity found between linarin and acacetin is suggested that all compounds shown certain interaction with the opioid receptors, probably with the $\mu$-subtype. Moreover, most of the compounds were predicted as non-mutagenic in both Derek and Sarah, with exception of caryophyllene oxide, for which Sarah gave an out of domain result.

Thus, these compounds isolated from Mexican plants represent a new benchmark in the search for compounds that can interact with opioid receptors, due to the fact that most of them have analgesic or antinociceptic activity with low acute toxicity, most likely by interaction with opioid receptors, without the fulfil of structural requirements previously identified for these kind of compounds. 

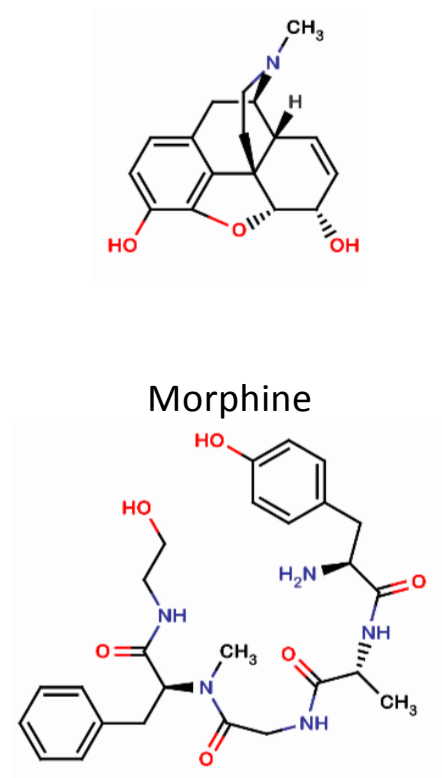

DAMGO<smiles>COc1ccc(-c2cc(=O)c3ccc(O)cc3o2)cc1</smiles>

Acacetin

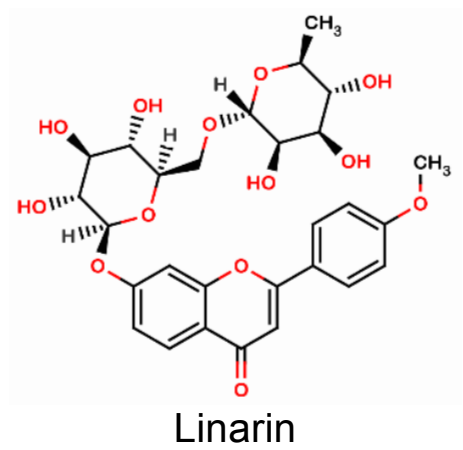

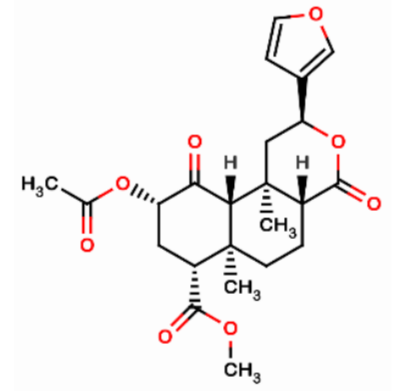

Salvinorin A

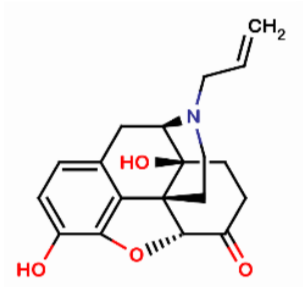

Naloxone

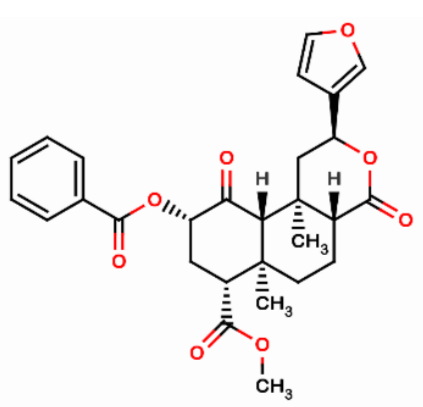

Herkinorin

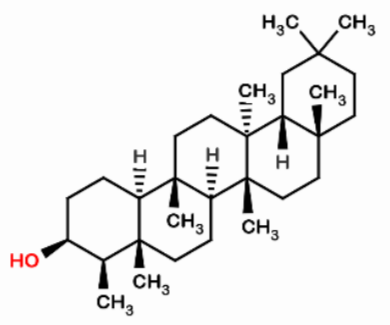

Epi-friedelanol

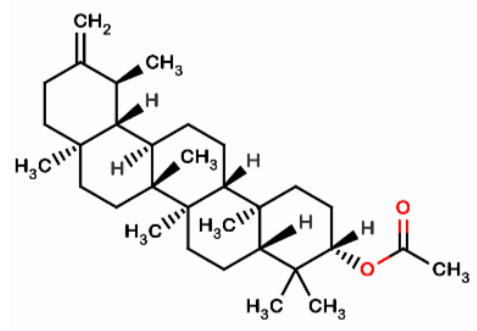

Taraxteryl acetate

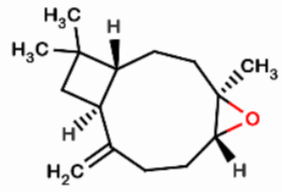

(-)- $\beta$-Caryophyllene epoxide

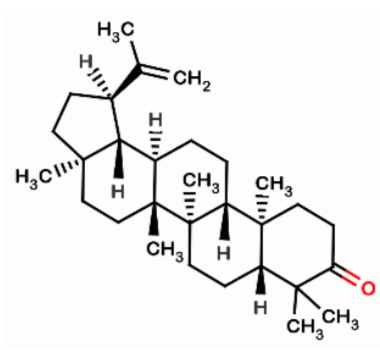

Lupenone

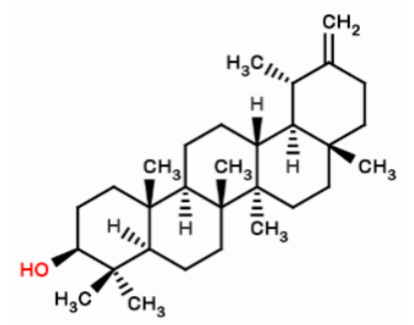

Taraxasterol anthesterin

Fig. 1. Molecules studied in this work. 
The predictions of mutagenicity performed with the software Sarah and Derek from Lhasa Limited are summarized in Table 3. These complementary toxicity predictors are designed to provide the necessary information for decision making under the ICH-M7 guidelines. While Sarah is a statistical-based predictor, Derek uses an expert knowledge-based method. Although both methods have the same endpoint, the way they reach a conclusion is different; therefore they are not redundant but complementary. Results are presented as positive (red) or negative (green) boxes. The associated description substantiates the prediction. In addition, in Sarah a percentage of confidence is provided. Taking together, this information allows to derive a conclusion on the predicted toxicity of each compound.

Based on this data, and according to Lhasa's guidelines, Derek predictions can fall on any of these categories: Certain: There is proof that the proposition is true; probable: There is at least one strong argument that the proposition is true and there are no arguments against it; plausible: The weight of evidence supports the proposition; equivocal: There is an equal weight of evidence for and against the proposition; doubted: The weight of evidence opposes the proposition; improbable: There is at least one strong argument that the proposition is false and there are no arguments that it is true; impossible: There is proof that the proposition is false.

If independent methods arrive to similar conclusions to the same endpoint then the accuracy of the results can be increased. For example, when Sarah and Derek are used together the accuracy is as high as $90 \%$ [17]. If the independent methods were always in agreement, there will be no need to apply both.
However, when the conclusions are contradicting, the information behind the conclusions need to be analyzed to discriminate why they are contradicting and derive a justified conclusion.

For the reference molecules morphine and naloxone, Sarah predicts they are mutagenic, salvinorin A and herkinorin are equivocal, and DAMGO is predicted inactive with $45 \%$ confidence. Among all the other compounds, acacetin is predicted inactive with higher confidence. Caryophyllene oxide is out of domain, and all the other molecules are predicted also inactive with around $25 \%$ confidence. In turn, Derek predicts all the compounds inactive, except for caryophyllene oxide that is predicted inactive with unclassified features. This quick but well substantiated overview of the toxicity profile suggests that none of the molecules studied here are predicted to be mutagenic.

Closer look at Derek's prediction for acacetin shows that not only there are not structural alerts for mutagenicity but also there were not unclassified or misclassified features. In turn, Sarah predicts acacetin as negative in a mutagenicity in vitro assay with $38 \%$ confidence. To arrive to this conclusion, Sarah searches for fragments with known mutagenic risk factor. As an example, Fig. 2 shows relevant molecules from the training set used within Sarah to come to the conclusion that acacetin will be inactive in the bacterial in vitro (Ames) mutagenicity test.

The central analgesic activity of molecules can be studied in vivo by means of thermal stimuli with the hot plate test in mice [25]. In turn, peripheral analgesic activity can be evaluated through the acetic acid-induced writhing test in vivo [26]. Other ways to study the analgesic or antinociceptive activity are the tail-flick test and formalin-induced paw licking test,

Table 2. Predicted $\mathrm{LD}_{50}$ oral in rat and mutagenicity of compounds with analgesic or antinociceptive activity from mexican plants and reference molecules estimated with "TEST" software.

\begin{tabular}{lccccc}
\hline & \multicolumn{3}{c}{${\text { Oral } \mathrm{rat} \mathrm{LD}_{50}{ }^{\mathrm{a}}}^{\text {Mutagenicity }^{\mathrm{a}}}$} \\
\hline Compound & $-\mathrm{Log} 10(\mathrm{~mol} / \mathrm{kg})$ & $\mathrm{mg} / \mathrm{kg}$ & $\mathrm{mmol} / \mathrm{kg}$ & & - - $^{\mathrm{b}}$ \\
\hline Morphine & $3.08,2.932^{\mathrm{b}}$ & $235.14,335.28$ & $0.82,1.17^{\mathrm{b}}$ & $0.47,0^{\mathrm{b}}$ & - \\
Salvinorin A & 2.75 & 772.53 & 1.78 & 0.32 & - \\
Herkinorin & 2.41 & 1942.32 & 3.92 & 0.31 & - \\
DAMGO & 2.36 & 2234.67 & 4.23 & -0.00 & - \\
Naloxone & 2.82 & 492.65 & 1.50 & 0.44 & - \\
Acacetin & 3.19 & 171.37 & 0.60 & 0.18 & - \\
Epi-friedelanol & 2.29 & 2204.82 & 5.14 & 0.29 & - \\
(-)- $\beta$-caryophyllene oxide & 1.97 & 2357.87 & 10.7 & 0.09 & - \\
Linarin & 2.29 & 2988.78 & 5.04 & -0.03 & - \\
Taraxasteryl-acetate & 2.11 & 3614.01 & 7.70 & 0.12 & - \\
Lupenone & 2.45 & 1522.42 & 3.58 & 0.19 & - \\
Taraxasterol & 2.29 & 2202.73 & 5.16 & 0.07 & - \\
\hline
\end{tabular}

${ }^{\text {a }}$ Predicted values.

${ }^{\mathrm{b}}$ Experimental values. Oral rat $\mathrm{LD}_{50}$ : Amount of chemical ( $\mathrm{mg} / \mathrm{kg}$ bodyweight) that causes $50 \%$ of rats to die after oral ingestion. Ames mutagenicity: A compound is positive for mutagenicity if it induces revertant colony growth in any strain of Salmonella typhimurium. 
Table 3. Predicted mutagenicity of compounds with analgesic or nonciceptin activity from Mexican plants and reference molecules, estimated with Derek and Sarah Nexus.

\begin{tabular}{lll}
\hline Derek & Sarah (Model - 1.1.19) \\
\hline The query structure does not match any structural alerts \\
or examples for (bacterial in vitro) mutagenicity in Derek. \\
$\begin{array}{l}\text { Additionally, the query structure does not contain any } \\
\text { unclassified or misclassified features and is consequently } \\
\text { predicted to be inactive in the bacterial in vitro (Ames) } \\
\text { mutagenicity test. }\end{array}$
\end{tabular}

\section{Herkinorin $-0-0$ Inactive}

The query structure does not match any structural alerts or examples for (bacterial in vitro) mutagenicity in Derek. Additionally, the query structure does not contain any unclassified or misclassified features and is consequently predicted to be inactive in the bacterial in vitro (Ames) mutagenicity test.

DAMGO
The query structure does not match any structural alerts
or examples for (bacterial in vitro) mutagenicity in Derek.
Additionally, the query structure does not contain any
unclassified or misclassified features and is consequently
predicted to be inactive in the bacterial in vitro (Ames)
mutagenicity test.

Naloxone

\section{$-0-\square$ Inactive}

The query structure does not match any structural alerts or examples for (bacterial in vitro) mutagenicity in Derek. Additionally, the query structure does not contain any unclassified or misclassified features and is consequently predicted to be inactive in the bacterial in vitro (Ames) mutagenicity test.

\section{Equivocal}

The compound is predicted to be equivocal with -confidence for the 'Mutagenicity in vitro' endpoint in the model. Supporting hypotheses containing similar examples from the training set have been found.

\section{-000 Negative}

The compound is predicted to be negative with $45 \%$ confidence for the 'Mutagenicity in vitro' endpoint in the model. Supporting hypotheses containing similar examples from the training set have been found.

\section{Acacetin \\ $-0-\square$ Inactive \\ The query structure does not match any structural alerts or examples for (bacterial in vitro) mutagenicity in Derek. Additionally, the query structure does not contain any unclassified or misclassified features and is consequently predicted to be inactive in the bacterial in vitro (Ames) mutagenicity test.}

\section{$+\oplus+ \pm$ Positive}

The compound is predicted to be positive with $100 \%$ confidence for the 'Mutagenicity in vitro' endpoint in the model. This is based on an exact match with a compound found in the training dataset. 4 supporting hypotheses were also found and are displayed for information.

\section{$-0 \square 0$ Negative}

The compound is predicted to be negative with $38 \%$ confidence for the 'Mutagenicity in vitro' endpoint in the model. Supporting hypotheses containing similar examples from the training set have been found. For the hypotheses indicated, the local activity signal generated from the most similar compounds to the query compound contradicts the overall activity signal for the hypothesis. $\beta$-friedelanol

\section{$-0-0$ Inactive}

The query structure does not match any structural alerts or examples for (bacterial in vitro) mutagenicity in Derek. Additionally, the query structure does not contain any unclassified or misclassified features and is consequently predicted to be inactive in the bacterial in vitro (Ames) mutagenicity test.

\section{-000 Negative}

The compound is predicted to be negative with $25 \%$ confidence for the 'Mutagenicity in vitro' endpoint. Supporting hypotheses containing similar examples from the training set have been found. 


\begin{tabular}{|c|c|c|}
\hline & Derek & Sarah (Model - 1.1.19) \\
\hline Taraxasteryl acetate & $\begin{array}{l}\text { The query structure does not match any structural alerts } \\
\text { or examples for (bacterial in vitro) mutagenicity in Derek. } \\
\text { Additionally, the query structure does not contain any } \\
\text { unclassified or misclassified features and is consequently } \\
\text { predicted to be inactive in the bacterial in vitro (Ames) } \\
\text { mutagenicity test. }\end{array}$ & $\begin{array}{l}\text { The compound is predicted to be negative with } 24 \% \\
\text { confidence for the 'Mutagenicity in vitro' endpoint. } \\
\text { Supporting hypotheses containing similar examples from } \\
\text { the training set have been found. }\end{array}$ \\
\hline
\end{tabular}

${ }^{\text {a }}$ Contains unclassified features. Specie: bacterium. Endpoint: Mutagenicity in vitro.

both in mice [27,28] [29]. Closer look at the biological activity data of the molecules studied in this work shows that all these compounds have been evaluated on either of these pain-related biological endpoints. Table 4 shows in vivo biological activity values for each of the molecules studied here. Interestingly, some of these compounds are used in human consuption, for example $\beta$-caryophyllene epoxide is a food additive approved by FDA as flavoring substance.

Acacetin is an $O$-methylated flavone isolated from Robinia pseudoacacia and Turnera diffusa among other plants, it exhibits anti-inflammatory as well as anti-nociceptive properties [30], and is widely investigated as part of the traditional Chinese pharmacopeia [31]. Robinia ( $R$. pseudoacacia) contains a toxic lectin on its seeds; it has been observed that horses that ingest this plant present anorexia, depression, weakness, and cardiac arrhythmia, among other effects. However, this plant could be investigated for health conditions where these effects are desirable, for instance to investigate its effect on weight management. The flowers however are eatable. Acacetin produces a significant and dose-dependent nociception inhibition of the writhes. Also, acacetin inhibits licking and shaking associated with nociceptive behavior, mainly in the inflammatory phase of the formalin test. At the unique dose of $56.2 \mathrm{mg} / \mathrm{kg}$, shows the maximal efficacy in the writhing and formalin tests, and it was compared to the antinociceptive response produced by the same dosage of tramadol [32].

Lupenone is a derivative of the naturally occurring triterpene lupeol isolated from a variety of plants such as Acacia visco, Abronia villosa and Mangiferae Mangifera sp. As its precursor, lupenone is an antibiotic and anti-inflammatory agent but it has also been found to be cytotoxic against in vitro human adenocarcinoma and melanoma models. Interest in developing lupeol-based anti-neoplastic agents, has leaded to the discovery of highly active derivatives [33]. Intraperitoneal administration of lupenone produces a dose-related and significant inhibition of acetic acid-induced abdominal constriction in mice. Approximately 50\% inhibition of nociception is showed with $5 \mathrm{mg} / \mathrm{Kg}$ for lupenone; with $10 \mathrm{mg} / \mathrm{Kg}$ results in a inhibition of 
Structure
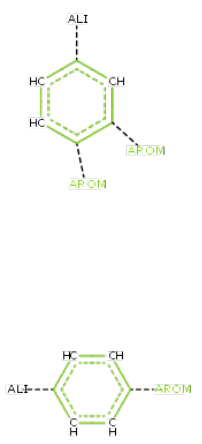

Example

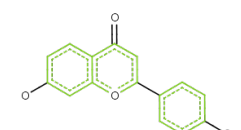

\&

negative

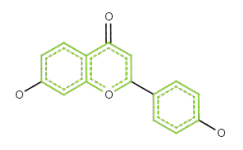

\&
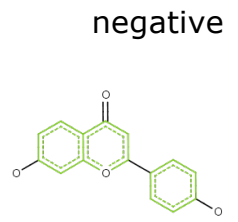

\&

negative

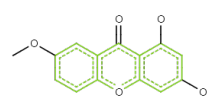

a

positive
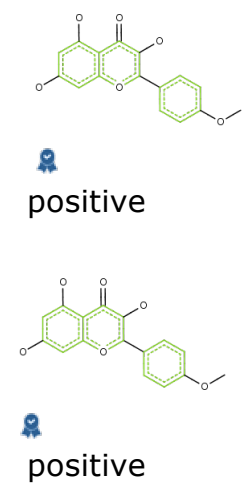

Confidence

/ examples

$16 \%$ / 576

$22 \% / 185$

$52 \% / 3117$

Fig. 2. Hypotheses for acacetin.

nociception ranging from 60 to $65 \%$ (Table 4). Pre-treatment of mice with opioid receptor antagonist, completely reverses the antinociceptive effects of lupenone, thus showing the opioid receptor mechanism for nociception. Also, lupenone exhibits 35.6 and $51.2 \%$ inhibition of nociception response in the acute and chronic phases, respectively [34].

Epi-friedelanol (also known as epi-friedelinol) is a triterpenoid found in a wide variety of plants. It has been reported to exhibit anti-inflammatory [35], antifungal [36] and antileishmanial properties [37]. Epi-friedelanol has better inhibition nociception values than diclofenac sodium $(10 \mathrm{mg} / \mathrm{kg})$ in the pain's early phase in formalin-induced paw licking test. The inhibition of writhing at $45.83 \%$ is considerable for acetic acidinduced writhing test [38].

Linarin is a flavonoid glycoside found in Valeriana officinalis which has sedative and sleep-enhancing properties that are potentiated by simultaneous administration of valerenic acid [39], acting as a second order positive modulator of $\mathrm{GABA}_{\mathrm{A}}$ receptors. Linarin exerts a significant protective effect from the dose of $50 \mathrm{mg} / \mathrm{Kg}$ (45\% nociception inhibition) in the acetic acid-induced writhing test, and has a maximum nociception inhibition value at a dose of $200 \mathrm{mg} / \mathrm{kg}(57 \%)$. Linarin $(100 \mathrm{mg} / \mathrm{kg})$ significantly increases the reaction time of mice by $55 \%$ in the hot plate test. A pretreatment with naloxone antagonized the analgesic effects of the linarin. The inhibitory effect of naloxone, a specific antagonist of morphinic receptors, on the analgesic activity of linarin suggests a morphine-like activity profile [40].

Taraxteryl acetate, a taraxasterol derivative, shows notable antinociceptive activity (Table 4). At $10 \mathrm{mg} / \mathrm{kg}$ dose, taraxasteryl acetate exhibits higher activity than acetylsalicylic acid (300 $\mathrm{mg} / \mathrm{kg}$ ) in the tail-flick test, as well as in the acetic acid-induced writhing tests. Moreover, antinociceptive activity of taraxasteryl acetate $(10 \mathrm{mg} / \mathrm{kg})$ is close to that of morphine $(10 \mathrm{mg} / \mathrm{kg})$ in the tail-flick test. The highest activity exhibiting taraxasteryl acetate is considered for good antinociceptive properties [41].

(-)- $\beta$-caryophyllene epoxide is a sesquiterpene found in most plants from the genus Cannabis and is the component which drug-sniffing dogs identify with marijuana [42]. The non-epoxide analogue is widely present in several spices from pepper, cloves, rosemary, basil and lavender; the epoxide is used as food flavoring [43]. Pretreatment with caryophyllene oxide in the hot plate test does not produce any significant changes of paw licking time in the post-treatment early phase. However, in the late phase, the caryophyllene oxide has a dose-dependent and significant increase in licking time treated in mice. The maximum activity is observed with caryophyllene oxide at the $120 \mathrm{~min}$ time interval $(25 \mathrm{mg} / \mathrm{kg}$ bodyweight). Caryophyllene oxide has centrally and peripherally mediated analgesic properties, inhibiting pain in the acetic acid-induced writhing test (Table 4). Further pharmacodynamic investigations are required to understand the analgesic mechanisms [44].

Comparing the reference molecules shown here, the seven molecules under investigation are structurally different, for example, some of them have opioid activity but does not contain all the accepted pharmacophore features for those receptors, such as a positively charge heteroatom and an aromatic moiety. Thus, investigation of binding modes and structural-activity relationship studies are warranted. Given the structural diversity, the nociception activities and the low predicted toxicity of the natural products studied here, they represent a promising hit compounds for further development. 
Table 4. Biological activity of compounds with analgesic or nonciceptive activity from Mexican plants and reference molecules.

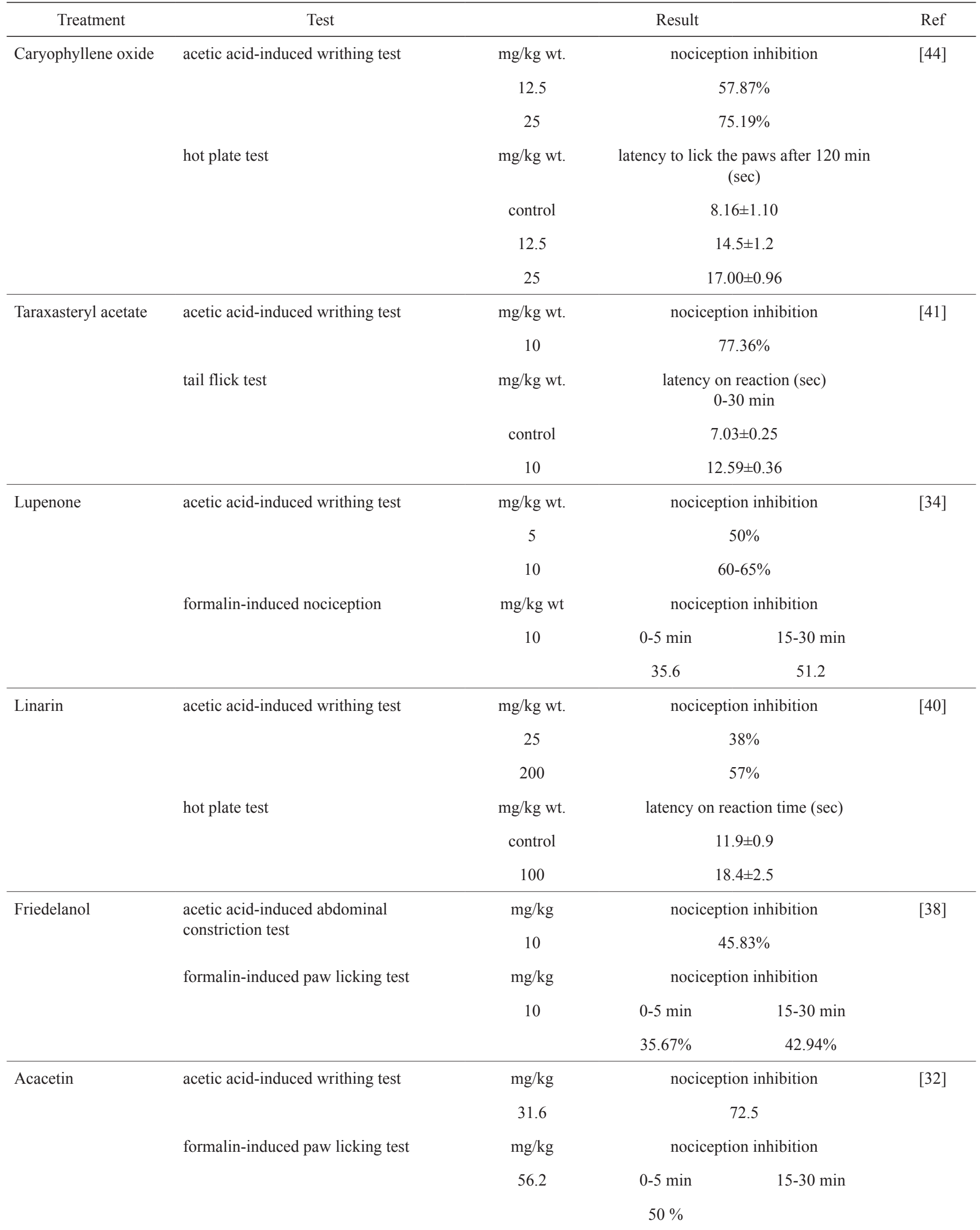


In conclusion, molecules searched in the UNIIQUIM with nociception activity represent structurally diverse molecules including flavonoids and terpenes. There are indications that lupenone, linarin and taraxteryl acetate extern their nociception effect via opioid receptors. However, for other natural products from Mexican plants with nociception activity the biological pathways involved on this activity need to be explored. Regarding toxicity profile, all the compounds studied do not represent a mutagenicity risk. Some molecules like $\beta$-caryophyllene are FDA approved flavor chemicals. The structural diversity of these molecules, their common nociception activity and the predicted safety profile as non-mutagenic agents highlights the importance of these molecules for further studies on the search of analgesic and nociception effects.

\section{Methods}

Molecules were searched and obtained from the UNIIQUIM database. UNIIQUIM database aims to collect and organize chemical, phytochemical, structural, and biological information of natural products produce for over 75 years in the Institute of Chemistry at the National Autonomous University of Mexico. The database can be searched online at http://uniiquim.iquimica.unam.mx/. Search of compounds with analgesic or nociceptive activity rendered seven compounds shown in Fig. 1.

Prediction of oral $\mathrm{LD}_{50}$ in rat and mutagenicity was performed using TEST (4.1) (Toxicity Estimation Software Tool). In addition, mutagenicity was also predicted with Derek Nexus (v.5.0.2) and Sarah Nexus (v.2.0.1) from Lhasa Limited.

The methodologies implemented in TEST (4.1) are hierarchical clustering, FDA, and nearest neighbors. Details of these methods are described elsewhere [45] and are briefly described here.

Hierarchical Clustering. This method uses Ward's Minimum Variance Clustering Method making a series of $\mathrm{n}$ clusters which has only one chemical of $\mathrm{n}$ chemicals, so for the training set there will be $n$ clusters, and the variance of test is the sum of the variance of the individual clusters

$$
V(l) \equiv \sum_{k=1}^{m} v(k, l)
$$

where $v(k, l)$ is the variance of cluster $\mathrm{k}$ at step 1 . Each of the following steps adds two clusters together to one cluster so the increase of the variance over all cluster is minimized

$\min V(l+1) \equiv V(l+1)-V(l)=v\left(k^{\prime}, l+1\right)-v\left(k_{1}, l\right)-v\left(k_{2}, l\right)$

where clusters $k_{1}$ and $k_{2}$ join together at step $l$ to make cluster $k^{\prime}$ at step $l+1$ the process of combining clusters continues until all of the chemicals are into a single cluster. Then, all cluster are analized by a genetic algorithm to determine the optimal descriptor set to obtain the toxicity values of the chemicals within the cluster. The maximum number of descriptors is $n_{k} / 5$.
Prior the genetic algorithm the model are optimized by means of checking for outliners, removing constant descriptors, correlated descriptors, and linearly dependent descriptors, then the predictions are made by "closest cluster from each step" approach in the hierarchical clustering.

FDA. In this method the predictions are made using new clusters constructed containing compounds with at least $75 \%$ of similarity coefficient with the test compound. A multiple linear regression model is constructed and the toxicity is predicted, the advantage of this method is that the training set is tailored to fit the test chemical and the disadvantage is that new model has to be generated for each test chemical. If the predictions cannot be made the cluster size is gradually increased from 30 up to 75 chemicals.

Nearest Neighbors. Considered the base line for more complex calculations. In TEST, this method has a fixed similarity coefficient $\left(S C_{\min }\right.$ is set to 0.5$)$. In this method the training cluster for the chemical test is constructed with the three closest chemical relative to the coefficient of similarity of the training set.

Derek and Sarah Nexus, developed by Lhasa Limited, were used to predict bacterial mutagenicity. Settings were left to default values. Derek is the expert toxicity prediction tool. Sarah is a statistical machine-learning methodology for the prediction of bacterial mutagenicity. Molecules are fragmented and reviewed for activity $v s$. inactivity using self-organizing hierarchical networks, whereby the model arranges relevant fragments. Models arrange relevant fragments into nodes (hypotheses). An overall prediction is obtained based on the prediction and confidence associated with each relevant fragment. Sarah provides a measure of confidence (which is correlated to expected accuracy) for each prediction it makes, for interpretation of a prediction by expert review.

Derek predictions are based on comparison of the information in a chemical structure to the toxicity Derek information or proprietary data in a knowledge base. Derek also highlights fragments of the query compound in order to illustrate the matches to patterns used to hold knowledge contained within Derek; an overall conclusion about the likelihood of toxicity in a structure and detailed reasoning information for the likelihood is so obtained. The prediction is generated by applying expert knowledge rules in toxicology to the data returned from the knowledge base.

\section{Acknowledgements}

This work was supported by the Institute of Chemistry; and Facultad de Quimica, PAIP under Grant number 5000-9163. AFMV and EISF thank to the Consejo Nacional de Ciencia y Tecnología (CONACyT) for providing scholarships. Authors thank ChemAxon, ChemSpider, and Lhasa for providing licenses or online freely available tools. We are indebted to Mizrain Solares, Nikholoz Kobahidze and Noe de la Rosa for providing chemical information. The authors also thank to 
Coordinación de Colecciones Universitarias Digitales (CCUD) for financial support.

\section{References}

1. Ortega A, Blount JF, Manchand PS J. Chem. Soc., Perkin Trans. 1 1982, 2505-2508.

2. Ji F, Wang Z, Ma N, Riley J, Armstead WM, Liu R Brain Res. 2013, 1490, 95-100.

3. Martinez-Mayorga K, Byler KG, Yongye AB, Giulianotti MA, Dooley CT, Houghten RA Euro. J. Med. Chem. 2013, 66, 114-121.

4. Yongye AB, Appel JR, Giulianotti MA, Dooley CT, Medina-Franco JL, Nefzi A, Houghten RA, Martinez-Mayorga K Biorg. Med. Chem. 2009, 17, 5583-5597.

5. Marmolejo-Valencia AF, Martinez-Mayorga K J. Comput. Aided Mol. Des. 2017, 31, 467-482.

6. Xu H, Partilla JS, Wang X, Rutherford JM, Tidgewell K, Prisinzano TE, Bohn LM, Rothman RB Synapse 2007, 61, 166-175.

7. Root J, Wakenhut AMLC, Siggins H, Katugampola S, Napier C Naunyn-Schmiedeberg's Arch. Pharmacol. 2012, 385, 1049-1052.

8. Kim HK, Nelson LS Expert Opin. Drug Saf. 2015, 14, 1137-1146.

9. Frampton JE CNS Drugs 2015, 29, 511-518.

10. Feher M, Schmidt JM J. Chem. Inf. Comput. Sci. 2003, 43, 218-227.

11. López-Vallejo F, Giulianotti MA, Houghten RA, Medina-Franco JL Drug Discov. Today 2012, 17, 718-726.

12. Medina-Franco JL, Martinez-Mayorga K, Meurice N Expert Opinion on Drug Discovery 2014, 9, 151-165.

13. González-Medina M, Prieto-Martínez FD, Naveja JJ, MéndezLucio O, El-Elimat T, Pearce CJ, Oberlies NH, Figueroa M, Medina-Franco JL Future Med. Chem. 2016, 8, 1399-1412 DOI: 10.4155/fmc-2016-0079.

14. Kim JH, Scialli AR Toxicol. Sci. 2011, 122, 1-6.

15. Auletta CS (2014). General Toxicology in Handbook of Toxicology Boca Raton, FL: CRC Press.

16. Walker JD QSAR \& Combinatorial Science 2003, 22, 415-421.

17. Barber C, Amberg A, Custer L, Dobo KL, Glowienke S, Van Gompel J, Gutsell S, Harvey J, Honma M, Kenyon MO, Kruhlak N, Muster W, Stavitskaya L, Teasdale A, Vessey J, Wichard J Regul. Toxicol. Pharmacol. 2015, 73, 367-377.

18. ICH-M7 International Conference on Harmonisation.

19. ICH-M7 (2015).M7 Assessment and Control of DNA Reactive (Mutagenic) Impurities in Pharmaceuticals to Limit Potential Carcinogenic Risk Guidance for Industry.

20. Retrieved April 20, 2015, from http://www.oecd.org/chemicalsafety/risk-assessment/validationofqsarmodels.httm 2004.

21. Dobo KL, Greene N, Fred C, Glowienke S, Harvey JS, Hasselgren C, Jolly R, Kenyon MO, Munzner JB, Muster W, Neft R, Vijayaraj Reddy M, White AT, Weiner S Regul. Toxicol. Pharmacol. 2012, 62, 449-455.

22. Rusyn I, Daston GP Environ. Health Perspect. 2010, 118, 1047-1050.
23. Hayes AN, Gilbert SG (2009).Historical milestones and discoveries that shaped the toxicology sciences. In Molecular, Clinical and Environmental Toxicology, Vol. 1, 20 (Ed Lunch A.). Basel, Switzerland: Birkhäuser Verlag.

24. Miller LL, Picker MJ, Schmidt KT, Dykstra LA Psychopharmacology 2011, 215, 455-465.

25. Eddy NB, Leimbach D Journal of Pharmacology and Experimental Therapeutics 1953, 107, 385-393.

26. Koster R, Anderson M, De Beer EJ Fedn. Proc. 1959, 18, 412-418.

27. D'Amour FE, Smith DL J. Pharmacol. Exp. Ther. 1941, 72, 74-79.

28. Davis PHPH, Davis P (1975). Flora of Turkey and the East Aegean Islands. Vol.5. Edinburgh University Press.

29. Hunskaar S, Hole K Pain 1987, 30, 103-114.

30. Ana G, Eduarda F, Jose LFCL, Lurdes M, Corvo ML Curr. Med. Chem. 2008, 15, 1586-1605.

31. Yuan-yuan Z, Bo-hua Z, Wei-guo S Chinese Journal of New Drugs 2014, 1053-1056.

32. Carballo-Villalobos AI, González-Trujano ME, López-Muñoz FJ Eur. J. Pain 2014, 18, 396-405.

33. Bhui K, Srivastava AK, Shukla Y (2010).Cytotoxic action of natural pentacyclic triterpenes on cancer cells: lupane-type compounds. In Pentacyclic Triterpenes as Promising Agents in Cancer (Ed Salvador J. A. R.). Azinhaga de Santa Comba, Portugal: Nova Science Publishers.

34. Talla E, Dabole B, Taiwe GS, Ngo Bum E, Mbafor JT, Atchade ADT, Malik R, Zulfiqar A, Sidiki N, Nguimbou RM, Choudhary MI Pharmacologia 2013, 4, 218-227.

35. Ramesh N, Viswanathan MB, Saraswathy A, Balakrishna K, Brindha P, Lakshmanaperumalsamy P J. Ethnopharmacol. 2002, 79, 129-132.

36. Viswanathan MB, Ramesh N, Ahilan A, Lakshmanaperumalsam y P Med. Chem. Res. 2004, 13, 361-368.

37. Yamamoto ES, Campos BLS, Jesus JA, Laurenti MD, Ribeiro SP, Kallás EG, Rafael-Fernandes M, Santos-Gomes G, Silva MS, Sessa DP, Lago JHG, Levy D, Passero LFD PLoS ONE 2015, 10, e0144946.

38. Ghosh S, Chattopadhyay D, Mandal A, Kaity S, Samanta A Med. Chem. Res. 2013, 22, 4347-4359.

39. Fernández S, Wasowski C, Paladini AC, Marder M Pharmacol. Biochem. Be 2004, 77, 399-404.

40. Martínez-Vázquez M, Ramírez-Apan T, Aguilar H, Bye R Planta Med. 1993, 62, 137-140.

41. Bahadır Ö, Çitoğlu GS, Šmejkal K, Dall'Acqua S, Özbek H, Cvacka J, Zemlicka M J. Ethnopharmacol. 2010, 131, 83-87.

42. Ross SA, ElSohly MA J. Nat. Prod. 1996, 59, 49-51.

43. Efsa Panel on Food Contact Materials EF, Processing A EFSA Journal 2014, 12, n/a-n/a.

44. Chavan MJ, Wakte PS, Shinde DB Phytomedicine 2010, 17, 149-151.

45. Martin TM, Harten P, Venkatapathy R, Das S, Young DM Toxicol. Mech. Methods 2008, 18, 251-266. 